\title{
Managing air quality - are we doing enough?
}

\author{
T. J. Chatterton, E. T. Hayes \& J. W. S. Longhurst \\ Air Quality Management Resource Centre, Faculty of Applied Sciences, \\ University of the West of England, Bristol, UK
}

\begin{abstract}
2005 marked the $10^{\text {th }}$ anniversary of the Environment Act that laid the foundations for the UK Local Air Quality Management regime. Two key events made it a significant year for air quality management in Europe. Firstly, the European limit value for $\mathrm{PM}_{10}$ came into force at the beginning of the year (followed later by widespread failure to comply with it). Later in 2005, after considerable debate, the European Commission launched its Thematic Strategy on Air Pollution, setting out its vision for air quality management up to 2020. In the context of these events, this paper looks at the state of air quality management in the UK, Europe and further a field and asks whether the nature of the current frameworks for air quality management and their implementation are any longer sufficient for tackling air pollution problems at a local, national and European scale.

Air pollution, in the UK at least, is largely a symptom of the country's transport problems with over $90 \%$ of Air Quality Management Areas in the UK being declared in relation to transport related sources. Despite the evidence of the strong relationship between transport, air pollution and AQMAs the government has 'revised' its 10-year transport plan, removing its commitment to a reduction in traffic and instead has committed itself to planning for considerable increases in road traffic. Given the predicted increases of traffic and its associated emissions is there any evidence to suggest that the air quality management regime is able to deliver the intended outcome of improved air quality?
\end{abstract}

Keywords: air quality management, transport, planning policy, thematic strategy, pollution, LAQM. 


\section{Introduction}

Development of the current framework for Air Quality Management (AQM) in the UK and Europe began in the early 1990s [1] developing in the latter half of that decade in to the UK National Air Quality Strategy and the European Framework and Daughter Directives. Now, one decade on, it is appropriate to examine the influence of this system and to make a judgement as to its efficiency and effectiveness. Have the aims and aspirations expressed ten years ago been fulfilled, and how might the system evolve over the next ten years?

\section{Has air quality management worked?}

The UK and wider European AQM schemes established in the 1990s can be viewed as well intended attempts to try to clean up what was seen at the time, as a relatively minor set of air quality problems that still remained following the great efforts made to control air pollutant emissions between the 1950s and the 1980s. However, in attempting to tackle this problem, it can be argued that the process has led to a new, more detailed perspective on air pollution, created by more widespread monitoring of new and different pollutants, the advance of computer technology aiding the building of sophisticated models, and new scientific insights into the composition, processes and health impacts of atmosphere, and that this clearer picture has made the UK's air pollution problem (at least seem) worse.

\subsection{Do we now have a bigger problem?}

At the time the UK National Air Quality Strategy was introduced in 1997, the general view of air quality in the UK was that, with the exception of ozone, air quality in the UK was generally good and that problems were predominantly limited to "occasional episodes of poor air quality which tend to occur with greater frequency and severity in heavily populated urban and industrial zones" [1]. Almost ten years later (January 2006) 182 (42\%) of the United Kingdom's 433 Local Authorities have Air Quality Management Areas (AQMAs) due to predictions that they would not achieve the Air Quality Objectives set out in the UK governments. When the process was being launched it was expected that few local authorities would proceed past the initial stage of the Local Air Quality Management (LAQM) Review and Assessment process and that only the largest metropolitan areas might require the declaration of AQMAs [2]. By the time that an evaluation of the LAQM process was undertaken in 2002 it was evident that the extent of air quality problems in the UK was greater than had been envisaged. The evaluation [3] found that in Round 1 of the Review and Assessment (R\&A) process, 71\% of Local Authorities had proceeded to a Stage 3 Assessment (for a full description of the R\&A process see Beattie et al [4]) and eventually 95 Local Authorities (22\%) found air quality problems that were significant enough to require the declaration of AQMAs during Round 1. However, there were still more to come. 


\subsubsection{Moving the perceived location of pollution}

The additional investigation of the air pollution situation in the UK had led to changes in the understanding of the sources related to high ambient pollution concentrations. Originally, it had been expected that most road transport related pollution issues would be associated with major roads with very high traffic flows. However, the problems found by some Local Authorities in Round 1 strongly indicated that these roads were usually wide, well ventilated and had no housing in close proximity to them (in the UK the Air Quality Objectives only apply where there is "relevant exposure" - and in the case of long-term averages that means residential properties) and therefore few problems were being found in these locations. However, far more problems than expected were being identified in small towns where narrow streets were congested with traffic flows as low as $10,000 \mathrm{vpd}$, or at junctions with relatively low flows, but increased emissions due to queuing traffic [3]. In the updating of the LAQM guidance for Local Authorities for Round 2, new advice was given to local authorities, directing them to look at previously unexamined areas, and in doing so they found previously undiscovered problems. This was not the only way in which new hotspots were found though.

\subsubsection{Changes in monitored concentrations}

One of the great successes of the LAQM process can be held to be the increase in amount of air quality monitoring undertaken by local authorities, and in relation to this, there has been a larger increase in the amount of monitoring conducted at locations that are directly relevant to public health. This in itself has led to a greater number of air quality problems being identified, however, over this period though, the UK also saw some 'unusual' meteorological conditions. 2003 was particularly notable for the summer heatwave which saw temperatures and pollution levels soar over most of Europe. This caused an increase in the number of pollution exceedences across the UK, but it also masked the fact that the UK also had a particularly polluted start to the year with a number of extended periods of stable weather. Following these conditions, data for 2004 was expected to show much lower pollution levels (comparable to those between 2000 and 2002) but this was not realised. Analysis by consultants for Defra [5] concluded that "while levels were generally higher in 2003 than in both 2001 and 2002, the increases were not outside the normal year to year variation seen in the data over a long period". Thus much of the monitoring carried out as part of Round 2 Review and Assessment work by local authorities showed significantly higher concentrations than in the previous round. In addition to this, it is also suspected that the predicted reduction patterns for some pollutants, particularly nitrogen dioxide, were over estimated for a number of reasons including unforeseen changes in emissions patterns [6] and therefore not only was the monitoring data used in Round 1 lower than in Round 2, but when predictions had been made for the concentrations in the future objective years, these were falsely optimistic and therefore many locations that were thought to be unlikely to have problems achieving the objectives turned out to be more polluted in the objective years than was first thought. By 2006, the official 
transition point from Round 2 to Round 3 of the LAQM process, 119 local authorities had declared Air Quality Management Areas (69 LAs having declared for the first time, 50 declaring new AQMAs in addition to having declared AQMAs in Round 1).

\subsection{Has there been an improvement in air quality?}

For the reasons outlined above, the picture being developed through the LAQM process, rather than showing improvements in air quality, has identified an increasing number of air quality hotspots. One of the ways in which it might be expected that improvements in air quality can be identified is through looking at the number of Air Quality Management Areas that are being revoked. Only a handful of local authorities have revoked AQMAs, and these have mainly been on the basis of improved monitoring or modelling work, or industrial sources being modified or closed down, rather than due to the implementation of effective action plans as part of the LAQM process. However, due to the need to ensure that it is action plans that have led to reduced pollution concentrations rather than other local effects or meteorological conditions, it is probably unlikely that many revocations due to targeted actions would have happened to date.

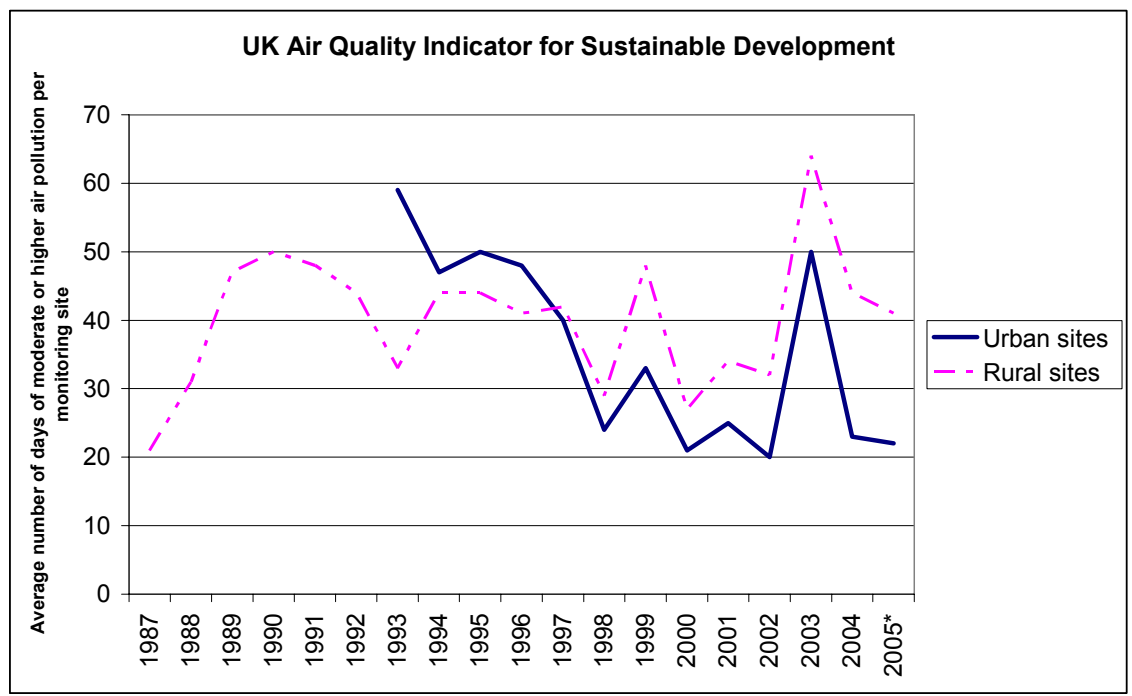

Figure 1: UK Air Quality Headline Indicator 1987-2005 (*2005 provisional) [7].

Another source of information for judging the extent of any improvements to air quality is the government's Headline Air Quality Indicator for Sustainable Development (see Figure 1) which shows that although very large reductions in urban pollution were made in the mid 1990s, during the active period of LAQM (1998 onwards) there is no distinct sign of improvements. It should be noted that 
the AQ indicator and the number of AQMAs reflect different aspects of air pollution with most of the UK's AQMAs being based on long-term (annual mean) pollution concentrations whilst the AQ indicator is based on the number of days when short-term episodes occur. Similarly there is a difference in the pollutants reflected by these statistics, with AQMAs being more heavily influenced by nitrogen dioxide, whilst the headline indicator tends to be dominated by $\mathrm{PM}_{10}$ and ozone [7].

\subsection{What caused the improvements in the mid-1990s?}

The large reductions in pollution levels in the mid-1990s are part of a trend that was running since the implementation of the Clean Air Acts in the 1950s and other activities that sought to tackle the old problem of urban 'pea-souper' smogs, and then continued to clean up the air as further problems due to acid deposition brought new problems to the fore. Domestic emissions were reduced through the increasing use of gas and electric central heating, whilst industrial processes became much cleaner through a mixture of fuel switching from coal to gas and the installation of abatement equipment.

These reductions in emissions from domestic and industrial sources have been on going and can be seen in emissions inventories from the 1970s onwards [8]. Over the first part of this period road transport related emissions of both $\mathrm{PM}_{10}$ and $\mathrm{NO}_{\mathrm{x}}$ grew before reaching a turning point in the early 1990s where they both began to decrease, despite increasing vehicle numbers and mileage. It was these decreases in road transport emissions between 1992 and 2000 (>50\% combustion related $\mathrm{PM}_{10}$, and almost $49 \%$ in $\mathrm{NO}_{\mathrm{x}}$ ) that led to the improvements in air quality shown by the urban headline indicator. These reductions were the result of the phasing in of European (Euro) emissions standards from 1991 onwards, in particular the introduction of catalytic converters, along with improvements in fuel quality with the phasing out of leaded petrol and the gradual reduction of sulphur in diesel. We are now reaching a point where the "low hanging fruit" in terms of reducing emissions through technology may be being reached. The compulsory fitting of particulate filter traps in the UK is still to come but it is suspected that whilst these may help reduce our remaining $\mathrm{PM}_{10}$ problems, it may do very little to tackle the nitrogen dioxide issue [6].

\section{From national to local}

In the previous section it has been argued that a considerable amount of improvement has been made by action at both a European and national scale. However, as stated earlier, in the UK at least, Local Air Quality Management has identified a large number of pollution hotspots that were previously invisible to local or national government, and are unlikely to be resolved through improvements made solely at a national level. These are the problems that the UK LAQM system was devised to address, but under current conditions can it be expected to work, and what sort of actions are being undertaken with enough success to give us hope for future improvements in air quality? 


\subsection{What are the tools available at a local level?}

The major pollution source leading to the declaration of AQMAs in the UK is transport, and where transport is not the principle pollution source, individual conditions tend to be so specific that it is difficult to make any generalisations. Therefore this section will concentrate specifically on attempting to reduce transport related pollution.

There are two different ways that transport management techniques can be categorised. Firstly on the basis of 'hard' and 'soft' measures: 'Hard' measures being those approaches that rely on changes to infrastructure or regulations, such as building new bypasses, changing road layouts, introducing vehicle bans, etc. 'Soft' measures (or 'Smarter Choices' as they are referred to now by the Department for Transport) are those methods that rely upon "techniques for influencing people towards more sustainable travel options, such as walking, cycling, public transport and car sharing" [9]. The second categorisation is effects-based rather than process-based. The main 3 aims are Demand Management, where the intention is to reduce the amount of journeys actually made, Modal Shift, where people are encouraged to change their mode of transport to more sustainable means (e.g. cycling, walking and public transport), and finally Limitation/Redirection where measures are put in place that mean that traffic no longer goes through certain areas (such as congestion charging, Low Emissions Zones or building bypasses).

\subsection{Local problems but national causes?}

Within the UK LAQM process it has been made clear that local authorities do not have a statutory responsibility to meet the air quality objectives [10] because they do not have control over transboundary pollution, or the largest transport and industrial sources of pollution which are managed by the national government through the auspices of the Highways Agency and the Environment Agency in England and Wales respectively. However, the tacit assumption that local authorities should be able to deal with all the problems outside the remit of these agencies (ignoring cost-effectiveness criteria for now) is not necessarily a solid one. Although LAs do control local roads (or at least County and Unitary authorities do), all these roads sit within a national transport system which is ultimately governed by national policies, policies which currently tend to favour increasing use of motor vehicles and for which the policy package has kept the cost of motoring reasonably constant in real terms for 35 years whilst the cost of public transport has increased by a third in real terms [11]. After years of not just giving free-reign to traffic growth, but actually (as it turned out) encouraging it through 'predict-and-provide' transport planning strategies [12], the coming to power of a new government in 1997 brought a sense of optimism as first the government introduced a White Paper [13] explicitly rejecting polices to provide for and accelerate the existing trends in traffic growth, and instead accepting that traffic growth needed "to be influenced rather than just accepted" [12].

Even though the following 10-year plan (launched in July 2000) appeared signal a commitment to further restraining action on traffic growth the reality 
was somewhat different. By the mid-2002 the government acknowledged that the Plan would not achieve its target of reducing congestion in England to below 2000 levels by 2010 and that traffic was now forecast to rise between 20 and $25 \%$ over the 10 -year period, and congestion by between 11 and $20 \%$. The revisions to the Plan also clearly stated that the key to the Department for Transport's environmental policy lay not in traffic reduction but solely through fiscal incentives to encourage the take up of cleaner vehicles [14].

Given that the government's policies appear unable to reduce traffic levels on a national basis it is hard to see how successful local government might be at controlling anything other than the most local journeys. Although the Highways Agency and Department for Transport are becoming increasingly involved in the air quality management process there is no sign that this is likely to help move the UK away from being a car dependent culture in the forseeable future, and thus may at best be being tough on the symptoms but not the causes.

\section{TRANSPORT - forwards or backwards?}

Over the last 25 years the UK has become increasingly car dependent, despite (arguably) being a success in terms of some views of the current "choice" agenda, the results of UK transport, land-use and social (e.g. education) policies has not resulted in indisputable benefits across either the environmental or the social arenas. Statistics quoted in the following section are based on information from the latest issue of the UK Department for Transport's 'Transport Trends: 2004' document [10].

\subsection{The rise of the motor vehicle}

Access to cars has increased rapidly, with $74 \%$ of people now having access to at least one in 2004 (compared to 59\% in 1980). Whilst this may possibly be seen as 'progress', within the contexts of both 'choice' and the economic and social equity elements of 'sustainable development' this is not necessarily the case in terms of health, pollution and congestion. The need for access to a car has become more important over this period as motoring has become significantly cheaper and more convenient than public transport. The failure to keep public transport as competitive as the motor car is not one that affects all sectors of society equally, the poor, the young, the old, women and the disabled all have much lower access to private vehicles than other groups in society, leading to some important social equity issues relating both to exposure pollution and access to the sources of that pollution.

Total traffic (vehicle kilometres) has increased by $79 \%$ between 1980 and 2003 (19\% since 1990). This is not simply due to increased car ownership, our pattern of car usage has changed and our drives to work, shopping and leisure activities all cover longer distances. However, it is interesting to note that the ability to travel longer distances by car for these activities is not necessarily a good thing, over this period the average time spent on each trip for work, shopping or education increased. The more we use cars the longer we are spending traveling - quite the opposite of the image often portrayed of them 
saving us time and making us more efficient! We are becoming increasingly unable to carry out the essential tasks in our lives sustainably as the use of bus, bicycle and foot to go to work, school or the shops have all dropped dramatically and increasing proportions of both car users and non-car users have reported experiencing difficulty in accessing essential facilities such as hospitals, doctors' surgeries, supermarkets, post offices and corner shops.

Whilst it is accepted that "the massive growth in road traffic, which could so easily have led to very serious air quality problems, has to a large extent been accompanied in recent years by air quality improvements due to enhanced abatement technology" [15] there are two problems with this. Firstly, there is a limit to the benefits that can be brought about by technological improvements, and this is likely to be reached soon as the continuing increase in road use begins outweigh the benefits from technological improvements. Secondly, new technology is often invented and introduced with a simple view of the problem that needs to be solved, sometimes failing to address secondary problems because they have not yet made their way on to the priority agenda such as (until recently) climate change, and sometimes the solutions even make these other problems worse.

\section{European policy}

Although the UK LAQM system pre-dates the implementation of the EU Framework and Daughter Directives on Ambient Air Quality, the EU legislation plays a significant role in under-pinning the UK system [4]. 2005 saw the European Commission begin to set out its future environmental policy with the release of the Thematic Strategies on Air Pollution (TSAP), and the Urban Environment (TSUE). These documents will be very significant in deciding where the environment gets placed in relation to economic and social goals. It can be considered fortunate that these strategies were passed at all, as intense lobbying from commercial and industrial sectors postponed and almost cancelled the adoption of the environmental strategies [16]. The arguments against taking a strong line on environmental protection were based on fears about the direct costs of implementing the strategies and the effects that they might have on the global competitiveness of European business, despite all potential scenarios laid out in the TSAP options showing significantly higher benefits to costs, including under the Maximum Technically Feasible Reduction scenario [17]. Consequently, the resulting strategies so far appear to be much weaker than many people outside the industrial lobbies had hoped for, and with the new accession countries having potentially joined more for reasons of economic growth rather than environmental protection it may be harder to rely on EU environmental legislation as a backstop in the future.

\section{Conclusions}

So how well are we doing at cleaning up our atmosphere? In terms of the most visible pollution such as black smoke, and the contributors to acid deposition we 
have done very well. These gains though have been largely brought about by the application of technical fixes (abatement technology, fuel improvements and changes etc.). What this is leaving us with is a still substantial amount of pollution within our cities, some of which may actually be significantly more harmful to health than the urban smogs of old, and an increasing amount of global pollution in the form of background surface ozone, and greenhouse gases.

What we have not seen are any significant changes to the way we live our lives and how we order our society that push us in the right direction for ensuring environmental protection. In fact it can be argued that increasing consumption of consumer goods, increased vehicle usage, reductions in access to key services and so forth are actually pushing society in the wrong direction, particularly in light of the example we set to the 'Developing World'. The discussions at a European level regarding the EU's environmental Thematic Strategies clearly showed that there is a very strong push towards maintaining our current trajectory in spite of the potential environmental consequences. Whilst we may very much like to believe in the possibility of business-as-usual scenarios, the impending prospect of climate change (and with it the likelihood that summers like 2003 will become normal by the 2040s) means that sooner or later we will have to change course.

What is clear though is that the move towards Local Air Quality Management came about at an appropriate time, that is, shortly before the big guns of pollution reduction ran out of (technical) ammunition. It may not have brought about any significant decrease in pollution yet, but it must be borne in mind that LAQM is not simply about reducing pollution it is, literally, about managing it. Therefore the development of our knowledge and understanding of air pollution, and ensuring it is put on the agendas of those professions that are responsible for the sources is as essential to the process as the final steps that will, hopefully, reduce pollution concentrations to levels that are acceptable to all.

\section{References}

[1] Longhurst, J. W. S; Lindley, S. J; Watson, A. F. R; and Conlan, D. E.; The Introduction of Local Air Quality Management in the United Kingdom: A Review and Theoretical Framework, Atmospheric Environment, Vol. 30, Issue 23, Pages p3975-3985, 1996.

[2] Bartlett, T.; Brown, T.; McDonald, T.; Price, F.; Local Authority Progress in Air Quality Management. Clean Air 27 (4), p97 - 98, 1997.

[3] Air Quality Management Resource Centre and Air Quality Consultants; Evaluation of the First Round of Local Air Quality Management Process, Report for Defra and Devolved Administrations, 2002.

[4] Beattie, C.I.; Longhurst, J.W.S.; Woodfield N.K.; Air Quality Management: Evolution of Policy and Practice in the UK as Exemplified by the Experience of English Local Government, Atmospheric Environment, Vol. 35, Issue 8, p1479-1490, 2001. 
[5] Air Quality Consultants; Was 2003 an Exceptional Pollution Year? UK Trends in Nitrogen Dioxide, Nitrogen Oxides and $\mathrm{PM}_{10}$ Concentrations Report for Defra, March 2004.

[6] Carslaw, D.; Evidence of an Increasing $\mathrm{NO}_{2} / \mathrm{NO}_{\mathrm{X}}$ Emissions Ratio from Road Traffic Emissions, Atmospheric Environment, Volume 39, Issue 26, p4793-4802, 2005.

[7] Defra, Press Release, Air quality indicator for sustainable development 2005 (provisional), http://www.defra.gov.uk/news/2006/060119a.htm, 2006.

[8] Goodwin, J.W.L.; Salway, A.G.; Dore C.J.; Murrells, T.P.; Passant, N.R.; Watterson, J.D.; Hobson, M.M.; Haigh, K.E.; King, K.R.; Pye, S.T.; Coleman, P.J.; Conolly, C.M.; UK Emissions of Air Pollutants 1970 to 2000, National Atmospheric Emissions Inventory, AEA Technology, July 2002.

[9] Department for Transport (DfT); Making Smarter Choices Work, June 2005.

[10] Department of the Environment (DoE); The United Kingdom National Air Quality Strategy, Department of the Environment and the Scottish Office, London, 1997.

[11] Department for Transport (DfT); Transport Trends: 2004 Edition, HMSO, 2005.

[12] Goodwin, P., Transformation of Transport Policy in Great Britain, Transportation Research Part A: Policy and Practice, Vol. 33, Issues 7-8, p655-669, 1999.

[13] Department for Transport (DfT); A New Deal for Transport - White Paper, HMSO, 1998.

[14] Begg, D. and Gray, D.; Transport Policy and Vehicle Emission Objectives in the UK: is the Marriage Between Transport and Environment Policy Over? Environmental Science \& Policy, Vol. 7, Issue 3, p155-163, 2004.

[15] Air Quality Expert Group; Air Quality and Climate Change: A UK Perspective (Draft), Report for Defra and Devolved Administrations, 2005.

[16] EuroActiv (EU Newsletter); 'High noon' for EU's Environment Policies, http:/www.euractiv.com/Article?tcmuri=tcm:29-142732-16\&type=News 20/07/2005.

[17] European Commission, Impact Assessment Annex to the Communication on the Thematic Strategy on Air Pollution, $\operatorname{COM(2005)446/7~final,~}$ 21/09/2005. 